\title{
MEASURING DISABILITY
}

\section{The ubiquitous desire for uniqueness}

As I write this, I have a clear view over the busy intersection between the main roads dividing the University of Bristol's central campus. The campus scene below is punctuated by constant flashes of brightness. The students that walk past are arrayed in an impressive spectrum of colour: yellow raincoats, lilac Puffa-jackets, red backpacks, floral umbrellas, purple windbreakers, neon blues and pinks offset by fresh white trainers. It is a paean to uniqueness and originality. For many of the vibrant individuals traversing the campus, to be described as normal or average would be akin to an insult. This is not a comment on the student mindset; it is a comment on the average mindset. A recent BBC Radio 4 documentary explained that 85 per cent of us would identify ourselves as above average, a huge increase compared with the 1950s, when only 50 per cent would make such a claim. ${ }^{1}$ Many have noted this societal shift - everyone wants to be unique. Yet when it comes to our health, we still strive to remain within the boundaries of normalcy. We might all desire to be uniquely dressed, uniquely intelligent or above average in certain prized areas, but nobody wants above-average cholesterol or abnormal test results. When it comes to our health, we all want to be normal.

This book's central thesis is that health measurements are validated if they are particularly amenable to calculability and easy measurement. In this chapter, I grapple with the epistemological implications of this claim as a contention which relates to two philosophical theses. Although this is a historical book with interdisciplinary influences, this chapter explicitly discusses the philosophical implications of my historical analysis. First, I argue that the naturalist position on disease and disability is undermined by consideration of how statistical normality is technologically constructed. The naturalist position maintains that the threshold level of normal functioning (the line of 
normalcy) is objective and value-free. However, by examining the data used to create the standards of normalcy, this book demonstrates that these thresholds - fundamental to technologies we use and trust - are often constructed through measurement instruments built with biased data sets. The threshold line of normal functioning that naturalists hold to be objective and value-free is thus also subject to bias and social evaluations. Furthermore, the changing use of appropriate reference classes has further concealed the variability of health within groups, simultaneously masking the social determinants of health that have affected these groups. That is, the judgements that we make concerning our biology are also normative. In sum, by exploring issues of trust in measurement through analysing the bodies used in defining the technical parameters of disability, I argue that the statistical definition of impairment is undermined by its technological construction. In relation to this, I argue that the need for objectivity in adjudicating and measuring disability has led to devaluation of individual experience and reduced understanding of the lifeworld of the disabled person.

Second, I argue that this presents a problem of 'mechanical' epistemic injustice. Measurement tools have been prioritised as authoritative and trusted ahead of individual testimony about personal experiences of health. While there was some acknowledgement of the individual, personal and intangible nature of breathlessness and hearing loss, the processes of testing for confirmation of pathology prioritised instrumental evidence over user voices. This, I argue, is an example of mechanical epistemic injustice. Epistemic injustice connotes the scepticism that greets certain (discriminated) groups' claims to knowledge. ${ }^{2}$ In healthcare, this can affect individuals' access to treatment as testimonies about their own bodies and health are placed under extra and unnecessary scrutiny. ${ }^{3}$ Such extra scrutiny and disbelief often attend the claims of the disabled, especially when claiming social support such as welfare benefits, which necessitates strict definitions of general disability and normalcy. ${ }^{4}$ However, this book does not attempt to theorise about disability generally. My attention is specifically on the historical experiences of adults who (broadly speaking) were unlikely to have identified as disabled. Furthermore, the primary focus here is on invisible but experiential disability as a category. Hearing and breathing are thus united through the processes of making these invisible sensorial experiences visible, which were characterised by a correspondent focus on objectivity and the use of precision measurement tools.

Although invisible, breathlessness and hearing loss are usually presumed to be somatic though in certain instances this is not the case. This kind of heterogeneity - inherent to disability - has long been problematic for philosophers attempting to detail a comprehensive metaphysics of disability. This chapter's 
consideration of mechanical epistemic injustice therefore holds additional relevance for those interested in mental illness, chronic illness and undiagnosable conditions.

Our understanding of what is normal in healthcare contains complex philosophical baggage. In what follows, I unpack these conceptual trappings. Further, I argue that the historical case studies in this book exemplify how the measurement of normalcy and the tools we use to make these measurements have shaped our understanding and judgements about disability. Illuminating the way that disability has been technologically constructed simultaneously sheds light on our understanding of normal functioning as a threshold and adds to our understandings of what medicine has historically and currently called 'normal'. This builds on philosopher Havi Carel's observation that 'the world of the ill is dependent upon the world of the healthy for its norms; and the world of the healthy is dependent on the world of the ill for the aberration of these norms.' I am concerned with exactly how these aberrations are constructed by technology through the creation of measurement standards, and aim to disentangle the processes and materials through which we make reliable and trusted measurements.

In the following section, 'Defining disease', I begin by outlining the main arguments relevant to philosophical attempts to define disease - naturalism and normativism. I bring sustained attention to the reference class problem in the section titled 'By no means average: the reference class problem' and explore the ways in which 'correcting' for attributes like sex, class and race (or not) impacts on the measurement of normalcy. In relation to the scholarship on reference classes, I discuss whether disability could ever be considered as a reference class and ask why it has not been previously considered to be a medically separable identity. When philosophers of medicine have focused on these definitional questions, they have tended to categorise disability under the heading of disease, using disease as an umbrella term which can encompass disability as pathology alongside disease in the narrow sense, as well as wounds and injuries and various other unhealthy conditions. Although taking this position allows us to do useful conceptual work on the metaphysics of disease, such a position has been critiqued by scholars of disability, who argue that disability is by no means necessarily 'a bad thing', an issue that I explore in the section on 'Defining disability'. After considering the ways in which Elizabeth Barnes's recent metaphysics of disability has problematised the concept of normalcy, I go on to argue that defining disability using a naturalistic framework is problematised not only by scholarship from disability studies but also by researches from the field of hedonic psychology. In the section on 'Well-being and disability', I argue that the existence of the disability paradox 
suggests that the measurement of disability is far more complex than naturalist accounts suggest. Finally, in the section on 'Disability and epistemic injustice', I argue that the move to define disability through technological construction has created a phenomenon I term mechanical epistemic injustice.

\section{Defining disease}

Within philosophy of medicine, defining disease has inspired a vast amount of literature which has crystallised around the naturalism versus normativism debate. In this section, I outline these two positions and argue that taking an interdisciplinary approach that encompasses insights from disability studies can allow for a compromise between these two dichotomous positions. Broadly speaking, naturalism holds that health and disease are objective biological facts that should not be influenced by 'our subjective evaluations of a state', while normativists maintain that health and disease are value-laden concepts. ${ }^{7}$ Before considering the various arguments against naturalism, we need to spend some time detailing the exact parameters of the naturalist account, which I start to set out below.

Naturalism is committed to the thesis that typical species' efficiency is objective and nonevaluative. Health and disease are hence objective biological facts. Disease is statistically defined biological dysfunction and health is the absence of disease. This is sometimes termed the 'negative conception of health' or the 'species norm account' and it holds that disease is simply an impairment of normal functional ability. ${ }^{8} \mathrm{~A}$ function is normal if it makes 'a statistically typical contribution ... to individual survival and reproduction.' ' The threshold of normal functional ability is determined by taking the statistical norm as an index of normal functioning. So, for example, we map the variability of human functioning onto a bell curve with cut points divided into units of standard deviation - which represent the positions low, medium, normal and high. If you fall below these thresholds that means you are sufficiently far from normal to be diseased. This is the dominant paradigm in medical practice and this account defines disability as 'a stable intrinsic property of subject $S$ that deviates from the normal functioning of the species to which $S$ belongs. ${ }^{10}$

Christopher Boorse is the best-known proponent of this view and has advanced it primarily through his development of the bio-statistical theory (BST). ${ }^{11}$ Jerome Wakefield's account of disorder as harmful dysfunction is like the BST in that it is naturalistic, that is, it rests on the idea of objective biological dysfunction (independent of value judgements). However, it differs in its conception of function and its inclusion of 'harm' as an essential criterion. ${ }^{12}$ However, there is not adequate space in this chapter to fully consider Wakefield's 
theory, particularly due to its specific focus on mental disorders, which are largely outside the scope of my analysis. It is important to note that in his 2010 chapter on disability Boorse does distinguish between disability and disease by making it clear that disability judgements vary with contextual factors independent of medicine. ${ }^{13}$ For instance, he acknowledges that 'the judgement about whether $\mathrm{x}$ is disabled is not always purely medical. ${ }^{14}$ However, his original iteration of the BST is consistently conflated with the medical model or 'common'-sense view. Therefore, I concentrate in the remainder of this chapter on Boorse's primarily proposed BST as representative of the medical model view on disability.

In the BST paradigm, the body (whether it be a human, animal or plant body) is made up of systems and sub-systems. 'System' is a broad term which includes organs, the nervous system and functions/systems of the mind such as memory. ${ }^{15}$ All the systems and sub-systems of the body ideally work towards the goal of survival and reproduction, and, for Boorse, normal function is the statistically normal contribution of any given system or subsystem towards this goal. Disease is dysfunction of the system (or sub-system), so disease is an internal state that is an impairment of normal functional ability. ${ }^{16}$ The inclusion of 'internal' here is important because it indicates that the aberration from normalcy is not caused by something external. For example, if I was to decide after Scotland winning a football game to celebrate by taking recreational drugs (equally unlikely scenarios) this activity might raise my heart rate. However, my temporary elevated heartrate would not count as disease unless it persisted after the effects of the drugs should have worn off. ${ }^{17}$ The advantages of the BST system lies in its practical use for clinical studies and clinicians, its broad and general applicability, its simplicity and apparent objectivity and political neutrality.

But do the dynamic and unpredictable functions of day-to-day normal physiology point towards a serious flaw in Boorse's account? That is, unless the BST is modified to situation-specific cases, it is unable to account for dynamic physiological functions. ${ }^{18}$ The philosopher Elselijn Kingma argues that this is a significant problem, pointing out that

the normal ranges of heart rate and cardiac output are very different on the occasions of sleeping (when both are low), and the less common occasion of strenuous exercise (when both are very high). Normal ranges of insulin production, glucose absorption and glycogen synthesis are very different depending on whether and what a person is eating and/or doing. Therefore, what the normal, healthy, correct or appropriate quantitative normal level for a specific function is depends on the situation or occasion too. ${ }^{19}$

Another criticism of the BST's statistical basis rests on the fact that there are conditions that affect many people (such as athlete's foot) which are 
statistically normal in the sense that they are widespread, but are nonetheless still considered pathological. The philosopher Rachel Cooper has pointed out the intrinsic difficulty of using the statistical norm as a guide to natural functioning, which 'makes it difficult for Boorse to include near universal diseases, for example dental caries, in his account.' ${ }^{20}$ Cooper's work on intellectual disability further demonstrates the extent to which economic concerns impact where the threshold is set on a bell-curve, as she shows how the cut-off point for mild intellectual disability shifted during the twentieth century in response to economic considerations such as the need for labour. ${ }^{21}$

Other philosophers have argued that the naturalistic account overgeneralises because there are many departures from normal functioning that are not considered to be markers of disease or disability. As Amundson has also pointed out, 'Better-than-average function is not usually labelled as abnormal even though it is statistically atypical. ${ }^{22}$ Barnes considers as an exemplar of this point the most successful Olympian of our time - swimmer Michael Phelps. ${ }^{23}$ Most people's wingspan is proportionate to their height, but Phelps is $6 \mathrm{ft} 4$, with a $6 \mathrm{ft} 7$ wingspan. He has hypermobile joints so his size 14 feet bend 15 per cent more than they should, and his muscles produce less lactic acid than is considered 'normal'. Moreover, Barnes points out that his lanky physique (also known as marfan syndrome) could put him at a higher risk for cardiac problems. ${ }^{24}$ This, she argues, means that the traits that allow us to be Olympic swimmers are not necessarily the same ones that promote survival. This conflicts with the naturalist view that considers a function to be normal only if it makes a statistically typical contribution to individual survival and reproduction; but it is surely counterintuitive to consequently argue that Phelps should be classed as disabled. This aspect of the naturalist account might also then consider being gay to be a disability (in the sense that it is not promotive of reproduction) and Barnes succinctly points out that any successful account of disability needs to be able to 'distinguish between being disabled and being gay.25 Given this unwelcome consequence of the BST, Barnes argues that in fact the naturalist account is implicitly normative. If we can accept that our definitions of disability are inevitably value-laden, could we define disability in terms of lack of ability?

Barnes would suggest not, as doing so would still result in an inadequate definition of disability. Disability as lack of ability does not hold for several reasons. First, we do not consider the common lack of certain abilities, or certain inabilities, to denote disability. ${ }^{26}$ For instance, I cannot touch my toes and never have been able to, a consequence of short hamstrings and my enjoyment of running, perhaps - but I am not considered disabled in virtue of that lack of ability. Second, a condition which means you are debilitated by a higher than 
usual sensitivity (for example, hyperacusis, which involves greater sensitivity to sound) is arguably an enhanced ability and yet it is still debilitating. Third, many disabilities are characterised by unpredictable and fluctuating capabilities, so that sometimes you can do something, but at other times you cannot; sometimes you can do it, but with assistance or the aid of a prosthetic, or in pain or at a cost to time or personal effort. ${ }^{27}$ The example of prosthetic assistance points to another flaw within to the naturalist account, which does not allow for the ways in which technologies (such as tool use and environmental design) change the ways that humans can function. Yet philosopher Ron Amundson believes that this is important: 'A weak person using an atlatl can throw a spear farther than a strong person without one. A weak person can walk faster on pavement than a strong person can walk on a sandy beach. ${ }^{28}$ Consideration of such factors may become more important in the future with the rise of transhumanism.

In summary, the BST has been criticised because of its inability to account for situation-specific functioning, the fact that statistical normalcy does not denote biological normalcy, its tendency to overgeneralise and its failure to successfully define enhanced or fluctuating disabilities. In addition, I argue that another profound criticism against the apparent 'objectivity' of the BST relates to the process of drawing the line of normal species functioning. There are two facets to my criticism. First, the threshold of normalcy presents the ideal as the normal so does not represent true variability among the population. I define this as a 'disability data gap' (see Chapter 3). Second, thresholds of normalcy are influenced by the inclusion of reference classes (see Chapter 5). In the next section I argue that while conventional medical distinctions by their nature must be arbitrary, the arbitrary choice of bodies to present certain classes does denote a significant flaw in the BST.

\section{By no means average: the reference class problem}

To briefly reiterate, the naturalist position holds that health is simply the absence of disease and that disease is simply an impairment of normal functional ability. A function is normal if it makes a statistically typical contribution ... to individual survival and reproduction. ${ }^{29}$ Therefore, the BST defines health as the absence of disease, and disease as the adverse departure from normal species functioning. Health is normal function, where normal function is the statistically typical contribution to survival and reproduction for my reference class. ${ }^{30}$ That is, 'The threshold for dysfunction is determined statistically, occurring at an arbitrarily chosen minimum level below the mean of the relevant reference class. ${ }^{31}$

It is this inclusion of reference classes that further complicated the issue. We do not tend to think of normalcy all in one go, rather we think about categories 
of difference or subgroups of people - reference classes. For instance, a physician considering whether patient Alex's inability to become pregnant is a problem would first need to know whether Alex was male or female and whether they were pre or post menopause. But what other factors do we take into consideration? When, for example, might race matter? Normality is always defined in relation to reference classes - normal function for that age, or sex, or race or species. And how we define and classify people into such groups is inherently value-laden.

Moreover, Cooper would argue that reference classes like age, sex and race are too broad for the purpose of defining disease and that they need to take into account other factors such as past training, environment, living conditions, as well as many other factors: 'Thus the organisms in a reference class must not only be of the same species, sex and age as the organism under consideration, but must also be of the same race and must have undergone similar training and have lived in the same kind of environment. ${ }^{32}$ That is, if you are a healthy but fairly sedentary person your resting heart rate would likely be slightly higher compared with someone identical to you who has lived a parallel life but pursued a professional athletic career. Similarly, if we took the average liver function of a group of alcoholics and used it to measure normalcy for the individuals therein, many members of this group would be considered normal, although through a broader population comparison they would be deemed pathological. That is, the statistically normal range in these groups would include function levels more broadly considered to indicate disease. There is thus a related (and already acknowledged) need to use separate reference classes for groups with distinct lifestyles (for instance, when measuring vital capacity in groups of smokers) so as to recognise disease that is distinct and unrelated to this lifestyle.

Therefore, the BST only works in reference to 'appropriate' reference classes. ${ }^{33}$ But what are the appropriate reference classes? And are appropriate reference classes equally appropriate for all conditions? While it seems intuitive to use categorical reference classes like age, sex and race, Steven Epstein argues that these classifications are based on a somewhat arbitrary supposition of relevance:

Out of all the ways by which people differ from one another, why should it be assumed that sex and gender, race and ethnicity, and age are the attributes of identity that are most medically meaningful? Why these markers of identity and not others? And are there differences among these types of difference, such that the same policy remedies may not be appropriate for each case $?^{34}$

To use a sporting analogy, we divide competitors into weight classes for boxing, but do not divide high jumpers by height though it seems that this would 
have relatively similar import on the competition. When using the BMI scale, we correct for age and sex. We make use of reference classes including height, weight, age, sex and race in lung function tests, but we do not use class; and we use of none of these categories in hearing tests. As we will see in the following chapters, this is a result of complex historical processes, with decisions regarding what categories to consider often having more to do with the measurement's development than with any supposedly relevant features of health.

For example, in epidemiological studies of heart disease, correcting for race, sex and class is standard practice. Janet Shim's study of the politics of heart disease illuminates the fact that

the custom of including racial categories, socioeconomic status, and sex in epidemiologic studies was so taken for granted that in presentations and conversations about their methods, researchers often referred simply to 'controlling for the usual suspects' as a shorthand gloss for the practice. ${ }^{35}$

Shim's account highlights the blurriness inherent in defining causation of disease as either biological or environmental. For instance, Shim explains that race in the context of epidemiology studies was not always considered to be of biological significance. Rather, it tended to be used as a proxy for the kinds of cultural differences and related health behaviours (such as diet) which were assumed to be relevant to the development of heart disease. ${ }^{36}$ Similarly, class was variously (and contentiously) defined through proxy measures such as income, occupation or education attainment. ${ }^{37}$ Conversely, sex (and especially oestrogen in the case of women) was consistently highlighted as being a meaningful biological factor relevant to heart disease, while the impact of gender (and its attendant impact on social biases, stresses, pressures and access to resources) was not considered relevant. This is despite the fact that researchers have linked the difference between men's and women's presentation of heart attacks to women's lack of reporting of chest pain due to (gendered) fears about wasting the doctor's time. ${ }^{38}$ Shim further describes a lack of interest in the 'emerging literature which asserts that sex and gender are not the clear, biological binaries we have imagined them to be. ${ }^{39}$ Yet this categorical approach risks obscuring the social causes of health inequities. Not only does it ignore the impact of biography and developmental plasticity on health, as Epstein explains, by 'valorizing certain categories of identity, they conceal others from view.'40

The work that reference class categorisation systems can do to obscure social causes of disease is an especially significant issue to consider in light of recent researches on allostatic load theory. Allostatic load refers to the concept that long-term stress exposure leaves a marked physiological stamp 
on the body, evidenced in biomarkers such as shortened telomeres. ${ }^{41}$ If, as seems to be the case, groups (such as racial groups) suffer from health inequalities not as a result of any factor related to their race but rather as a result of increased allostatic load caused by long-term stress, then we may need to consider whether using racial reference classes has obscured this social cause of ill health. We might also ask whether, if living under oppression is a significant determinant of health, we should categorise other social groups, for example those of lower socioeconomic status (or the disabled), as a meaningful reference class. This would be a politically charged move, as Epstein makes clear: 'Indeed, if social class were incorporated as a standard classifier, the political effects might be significant: because social class is not seen as a biological category, to call attention to differential health outcomes by class is to call attention to the effects of social inequality on health. ${ }^{42}$ Indeed, such processes of knowledge production have often been promoted explicitly as part of political agendas.

For instance, it is relevant to question whether grouping people into these categories affects the perpetuation of these categories. This is an increasingly relevant concern in the age of big data, which relies on such processes of categorisation. Chow-White and Green have argued that the development of genome technologies has resulted in an attendant acceptance of clear-cut racial boundaries purportedly correspondent to measurable genetic factors. Epstein points out the irony in the fact that since the sequencing of the human genome in 2000 demonstrated the commonality between humans, using racial categories to measure genetic difference has increased:

Unlike other species, including other primates, humans cannot be disaggregated into clearly defined genetic subspecies - meaning that the eighteenth-and-nineteenth-century racist and imperialist conception of humanity as divided into biologically discrete groups simply has no basis in fact. ${ }^{43}$

Yet Chow-White and Green point out that using racial categories as a surrogate measure in genetics is simply easier - at least for the purposes of the researchers. Moreover, data-driven processes' apparent objectivity masks the way in which 'the decision to group racial data into three large samples of Asian, African, and European requires a complex social calculus for groups at the boundaries. ${ }^{\prime 4}$ Similarly, understanding of sex/gender as existing on a spectrum rather than on a binary complicates its previous simple division. The apparent neutrality of big data disguises its ability to categorise and shape the social world and 'this seeming neutrality obfuscates domain assumptions and leaves cultural values and practices of power unexamined. ${ }^{45}$ 
Similarly, researchers such as Safiya Noble and Anna Hoffman have recently drawn attention to issues of fairness within algorithmic systems, demonstrating that technologies, like, for example, search engines, can work to architect and perpetuate structural biases. ${ }^{46}$ Prejudices, cultures, biases and decisions are thus invisibly embedded in digital products through the categorisation of big data. As well as reflecting inequalities in society, these processes can work to perpetuate them. One of the ways that we can start to recognise and deal with the categorisations that lead to data discrimination is through examining the historical classification and categorisation of relevant groups. This is particularly relevant within healthcare classification systems, which often split up the world into useful categories. Classification systems section the world and allow us to put things or people into neat sets of boxes, which then work in the promotion of knowledge production. ${ }^{47}$

My argument here is not just that the variable use of reference classes undermines the naturalist conception of disease, but also that their use may serve to essentialise inappropriate social classes, and through this process conceal causes of health inequality. Classification of entities like race, disease, disability and patients is highly controversial and extremely important, as in the process of being classified they are often fashioned as natural divisions. But when we read studies that purport to demonstrate a biological basis for inequality, it is worth thinking about the underlying motivations for classifying their subjects into different groupings. Medical classifications divide our world into convenient categories, shaping our reality. ${ }^{48}$ The process of categorisation and standardisation in knowledge classification systems has often been promoted explicitly as part of political agendas. Yet the objectivity and trust that we associate with numerical classification means that whatever classification schema these standards mark out becomes invisible as it upholds the categories it uses as inevitable, immutable, natural kinds - a process that philosopher Ian Hacking has described as 'Kind making.'49 To say that a kind is natural is to say that it corresponds to nature's architecture as opposed to human interests. There is much debate, however, over whether things like races, sexes or sex orientations are natural kinds, or if they reflect the classifying interests of humans.

These are accordingly referred to as Social Kinds, and while sex categories have until recently been accepted as being (on average at least) as binary, there are more long-term definitional difficulties associated with racial and ethnic categories. As Amundson puts it: 'We were not carving nature at its joints when we partitioned human variability into races. ${ }^{50}$ Epstein outlines the questions connected with this difficulty in healthcare classifications by asking: 'How many racial and ethnic categories are there? What about people 
who are multiracial or multi-ethnic?'51 To clarify, Kingma makes the point that we might be able to make a useful distinction here between ideas and objects. She explains:

Take, for example, race. We might make a distinction between the object race that is the existence of groups of people that share some (biological) differences, such as a difference in skin colour or ancestry - and the idea race, that is the practice of using certain physical characteristics to sort people into groups, and to use this classification for various purposes. The idea of race is the idea that sorting people into groups by, for example, skin colour, is a relevant means of classification. $^{52}$

This is the kind of sorting process that has been illuminated by the work of Lundy Braun, who has explained that racialised lung function measurements are rooted in white supremacist ideologies of difference between races. ${ }^{53}$ Race correction is literally programmed into the spirometer. It will not work unless you select race by either pushing a button, touching the screen or selecting race on a pull-down menu. It is unclear how the operator is meant to determine their patient's race. Moreover, because this function is 'black boxed', inside the machine as standard, many medics are unaware of how this process impacts on lung capacity measurements. This is just the kind of successful standard that disappears as a result of its success and becomes a ubiquitous and unremarkable aspect of scientific/industrial infrastructure. ${ }^{54}$ Yet its apparent irrelevance gives the lie to its significance, as it could affect claims for compensation for occupational disease. For example, if you are black, a lower lung function norm means that you could be deemed ineligible for compensation even with the same degree of lung damage as your white co-worker. This works either through a scaling factor (of up to 15 per cent) or through use of race-specific population standards, usage of which varies between different manufacturers and different regions. ${ }^{55}$

However, it may nonetheless be necessary to use these corrections to ensure we gain accurate information when we assess someone's health for the first time. As a tool for evaluating respiratory health the spirometer is very useful - it is necessary for diagnosis of COPD (complex obstructive pulmonary disease - an umbrella diagnosis of various lung diseases), for example. Moreover, it provides crucial information about the progression of an individual's illness over time. Normal reference population values are used for many reasons in medicine, not least because they offer easy and fast ways to assess health. Yet Braun concludes that we must move towards a more intersectional understanding of health inequality, with more consideration for how socioeconomic status affects lung function. She argues that 
by 'considering race, class, and gender as deeply intertwined and the lungs as sensitive indicators of lived experience, we can ask how global inequality affects respiratory health. ${ }^{56}$

Health inequalities are interconnected with the use of reference classes. As we will see in Chapter 5, using corrections for social groups as though they were biological groups was successfully employed to deny compensation to groups of miners. Simultaneously, failure to develop relevant reference classifications for women led to a lack of interest and research into women's lung health. In analysing these historical developments, it is necessary to take an intersectional approach. ${ }^{57}$ It is unhelpful to look only at one category (like gender) because by doing so we miss the fact that these categorisation processes are about power more than anything else. And I argue that considering the category of disability makes this clearer. We make use of various reference classes in various situations, but there are challenges in both establishing class membership and establishing class relevance. A further class we might consider is disability and considering the class of disability makes explicit that much of categorisation is about social power, not nature. As we saw previously, there are significant challenges in giving an objective naturalistic definition of disability.

\section{Defining disability}

When considering disability, the main proponents of naturalism take a similar position to that developed through the BST's account of normal functioning. The WHO's International Classification of Functioning, Disability and Health (2001) describes disability as entailing 'decrements in functioning': 'disabled people cannot do everything the average human being can do. $^{58} \mathrm{~A}$ paradigm example of this position in the context of philosophy of disability can be found in Norman Daniels's account, which holds that:

Disease and disability, both physical and mental, are construed as adverse departures from or impairments of species-typical normal functional organization or 'normal functioning,' for short. The biomedical sciences for humans, like the veterinary sciences for animals, study both the variation in the functional organization typical for our species and the departures from normal functioning that we call disease and disability. The line between disease and disability and normal functioning is thus drawn in the relatively objective and nonevaluative context provided by the biomedical sciences, broadly construed. What counts as disease or disability from the perspective of these sciences is largely free from controversy in the broad range of cases. ${ }^{59}$ 
This links us back to the second main concept of disease within philosophy of medicine - normativism. The normativist position maintains, against naturalism, that health and disease are essentially value-laden concepts. Historical examples of diseases with a shifting status are therefore reflective of society's changing values. An example of this kind of analysis is hysteria, which, it has been argued, was redefined as a non-disease condition not because of new biological information, but rather due to widespread changes in moral values. ${ }^{60}$ Another counterexample often proposed to naturalism is homosexuality, which for most of the twentieth century was classified as a disease in the Diagnostic and Statistical Manual (DSM) of the American Psychiatric Association. ${ }^{61}$ The naturalist response is that homosexuality and masturbation (a typical defining 'symptom' of hysteria) were never 'real' disorders in the first place, and so this is just a case of erroneous classification.

However, Cooper has convincingly argued that the assumption that disorders must be universal and evident throughout history to be 'real' is unjustified. ${ }^{62}$ For philosophers such as Cooper, Boorse's account of disease is fatally flawed. She offers an alternative account which suggests that a disease is a condition that fulfils certain conditions: it is a bad thing to have, it is unlucky that the patient has it and it is potentially medically treatable. ${ }^{63}$ By including disability under the category of disease, this account has attracted the ire of many disability scholars who take central issue with the implication that disability is either bad or unlucky. ${ }^{64}$

Disability studies thus poses a challenge to philosophy of medicine, but Kingma has pointed out it also offers a compromise between the two apparently dichotomous positions of naturalism and normativism. ${ }^{65}$ Disability studies generally tends towards a social constructivist position, which maintains that classifications originate from social and evaluative considerations, but does not necessarily argue that this means disability is somehow not real or cannot be described in an empirical manner. As philosophers Chin-Yee and Upshur have also pointed out, the disease concept's 'value-ladenness does not preclude the possibility of having a definition informed by empirical science. ${ }^{66}$ Before we attempt to outline such a definition of disability, that is, simultaneously empirically informed and socially constructed, we need to be clear about how disability is conceptualised within disability studies - and there are problems in defining the term disability even within the field. In disability studies, broadly speaking, the consensus on what constitutes disability is not a matter of human bodies but of the society that they are in. This view falls in line with the ideology inherent to social model thinking about disability, a way 
of thinking which has had a dramatic impact in advancing the political rights of the disabled in Britain.

The UK activism that led to the 1995 Disabilities Act was characterised by its use of the concept of the social model of disability, which presented a dichotomy between the medical and social model of disability. In disability studies, the medical model represents the imperialism of the medical community over the disabled and its attendant treatments and prosthetics. In opposition to this is the social model, a concept which was first coined by Mike Oliver in 1983. It has since become an influential social constructivist ideology that rests on the argument that it is society that oppresses and disables people on top of any impairment. The 'social model' was proposed by the Union of the Physically Impaired against Segregation (UPIAS) network, which was formed by disabled people who rejected the medical model of disability. The network was a small but hardcore disabled activist group with Marxist principles, working to replace segregated institutional facilities with independent living and working. ${ }^{67}$ The social model suggests that disability is not so much an abnormality as it is a difference; that there is no fixed 'normal', and instead people exist on a spectrum of ability. Thus, unlike the orthodox philosophical view, which (broadly speaking) tends to view disability as inherently bad, the social model views disability as a primarily socially motivated phenomenon.

This model attributes the difficulties that disabled people experience mainly to societal failures. According to the social model, therefore, the problem of 'disability' derives mainly from society's inability to adapt to a wide range of human capabilities, rather than from an individual's differences from a restricted definition of 'the norm'. Simply, when society treats disabled people as abnormal and consequently excludes them from opportunities in work or education and denies them control over their own living conditions and treatments, then they inevitably experience difficulties. The social model and its neat relocation of the 'problem' of disability in the environment has been an incredibly important tool in advancing the rights of the disabled in the UK and across the world. Its simplicity, however, has been identified by Tom Shakespeare as the 'fatal flaw' of the social model, and he has argued in detail about why he believes the 'strong' social model has become problematic, rigid and exclusionary ${ }^{68}$ It is worth noting here, as Robert Chapman has recently discussed, that the social model as defined by UPIAS still assumes a 'Boorsean' type account in its notion of impairment. ${ }^{69}$

Aligned with Shakespeare, Barnes has argued that the dichotomy between the social and medical model is too strong, and that it does not 
account for the full variety and divergence within characterisations of disability. In her book, she offers an alternative account, called the value-neutral model, which reframes (physical) disability as 'a way of being a minority body. ${ }^{70}$ Barnes thus argues for a moderate social constructivist view. To clarify this point, the social model is a version of social constructivism, but there are other socially constructed explanations of disability. For example, Kuhane and Savulescu's Welfarist account defines disability in a completely revisionary way, as 'a stable personal trait that tends to diminish a person's wellbeing relative to some given context. ${ }^{71}$ It was designed to put greater emphasis on the question of well-being, and to enable clearer thinking in contentious ethical cases involving disability. However, this account results in features of social inequality (such as being a woman in a sexist country) counting as a disability, while other cases of disability considered not to diminish well-being (such as Deafness) do not. For Barnes, this is incompatible with a workable philosophy of disability and should furthermore be dismissed because of its incompatibility with disability studies. That is, 'a philosophical theory of disability shouldn't be in the business of claiming that much of what is said about disability within the disability rights movement is analytically false. 72

The definition of disability given by the UN Convention of the Rights of Persons with Disabilities enacted in 2008 was similarly influenced by social constructionism and stated that 'disability results from the interaction between persons with impairments and attitudinal and environmental barriers that hinder their full and effective participation in society on an equal basis with others. ${ }^{73}$ This is similar to scholar Tom Shakespeare's 2006 iteration of disability as predicament, which allows for the idea that we should still try and avoid impairments if possible. He writes:

We are reminded that disability is extremely diverse and heterogeneous and that generalisations - 'disability is tragic' or 'disability is just another form of difference' - are usually misleading. A second point is that while many limitations experienced by disabled people are externally imposed restriction arising from inaccessible environments and social discrimination, there are also often intrinsic limitations to individual functioning that can only be overcome through the assistance of others, and not always even then. This form of life may not mean suffering, may not be incompatible with a good life, but might entail not being able to do everything that a person might want or hope to do. ${ }^{74}$

However, Barnes points out that if we are really trying to find a metaphysical account of what disability is, then all this view does is shift the burden 
of understanding from disability to impairment, and attempting to define impairment leaves us in the same position we were in when we critiqued the naturalist account - that is, seeking a metaphysical answer to the question 'what is impairment?'. ${ }^{75}$ She also points out that moderate social constructivist positions such as Shakespeare's do not mesh well with the idea of disability pride: 'it's difficult to maintain, simultaneously, that disability is something to be celebrated and that disability is something we ultimately want to get rid of. ${ }^{76}$

And yet I think one of the reasons that Shakespeare's view is so persuasive is that it appeals to what seems to be an intuitive or common-sense view of what disability is. However, Barnes has countered the temptation to rest our analysis on common-sense suppositions by pointing out that, historically, we have often made assumptions based on common-sense intuitions that we now think of as very wrong, and which were often made by a majority in a way that disempowered a minority. ${ }^{77}$ For instance, in the previous chapter we discussed the nineteenth-century science of craniometry and the way in which it was used to demonstrate differences in intelligence between 'races' and between men and women. The apparent 'objectivity' of the scientific data used in this pursuit was deconstructed by Stephen Jay Gould in The Mismeasure of Man. As well as arguing that numerical measurements were prioritised as markers of truth, Gould's work also highlighted the pliable ways in which reference classes can be used, particularly when measurement are 'corrected' for the relevant class. To exemplify this, Gould related the story of Paul Broca (1824-80), a renowned French physician and anthropologist, now best known for developing the concept of cortical localisation and the identification of 'Broca's area. He used lead shot measurements of cranial capacity and weighed brains in order to make the claim that the size of the brain correlated with intelligence. His claims were opposed by the Frenchman Louis Pierre Gratiolet, who argued that the size of the brain bore no relationship to intelligence. Gratiolet's challenge rested on his light-hearted point that 'German brains were on average 100 grams heavier than French brains so therefore brain size could not possibly correlate with intelligence. ${ }^{78}$ However, Broca was able to repudiate Gratiolet by applying corrections to French brains for non-intellectual factors that impact on the brain's size at death, including age, health, manner of death and body size. ${ }^{79}$

This case demonstrates the importance of relevant reference classes and shows how their inclusion or exclusion can allow for easy manipulation of data. Broca never used these corrections in his work on women's brains, for instance, although he realised that their smaller average body size could be impacting on 
his results. He reasoned that applying corrections to women was unnecessary because of the already established fact of women's inferiority, writing:

We might ask if the small size of the female brain depends exclusively upon the small size of her body... But we must not forget than women are, on the average, a little less intelligent than men, a difference which we should not exaggerate but which is, nonetheless, real. We are therefore permitted to suppose that the relatively small size of the female brain depends in part upon her physical inferiority and in part upon her intellectual inferiority. ${ }^{80}$

Broca's rationalisation of women's inferiority would have been considered eminently sensible and fair to many of his contemporary scientists and no doubt to much of the population living at that time. Barnes reasons that remarks like this should show us that we must be wary of relying on our intuitions when defining disability. As Barnes explains, our intuitions are informed by culture, 'And while that might (might!) not matter much when it comes to intuitions about logic or mathematics, it matters a great deal when it comes to intuitions about the well-being of oppressed groups ... And it is particularly suspect when it contravenes the testimony of many members of that disadvantaged group. ${ }^{81}$

Nonetheless, Barnes's value-neutral model of disability differs from the traditional social model view in that she denies that disability should be considered as on a par with social categories like race and gender. Rather, she argues (again allying herself with Shakespeare on this point) that there is a crucial somatic element to disability. She explains: 'we may not be able to give an account of disability based on objective similarities shared by disabled bodies. And yet what your body is like matters to whether you are disabled. It might not matter for gender or race - I take no stand on that here - but it does matter for disability. ${ }^{\prime 2}$ However, Barnes does aver that the categorisation of kinds and the importance we place on them are socially constructed even if the physical features are not. That is, classifying someone as disabled (at least physically) is

a matter of whether they in fact have particular objective bodily features. But the fact that these bodily features are important to us - the fact that they matter, and are considered relevant to the classification of someone as disabled - is due to the way we think about bodies, rather than some objective similarity between such bodies. And that's what it is, on my view, for disability to be socially constructed. $^{83}$

Thus, she concludes that it is the norms and practices which shape why we take certain bodies to matter that we should be analysing and questioning. ${ }^{84}$ 


\section{Well-being and disability}

Barnes maintains that disability is not something that makes you intrinsically worse off. She points out that there is a great deal of empirical evidence which suggests that

non-disabled people are extraordinarily bad at predicting the effects of disability on perceived well-being. Non-disabled people tend to assume that disability will have a substantial negative effect on perceived well-being, and that the perceived well-being of the disabled will be substantially lower than their own. But a substantial amount of research suggests that this is simply not the case. ${ }^{85}$

The gap between the way that people are defined as disabled and their own identification with this label is a repeated theme in this book. From the miners who believed themselves disabled by dust to the businessmen who argued that their telephones were the real source of their hearing difficulties, we will see multiple cases of individuals contesting the status of their dis/ability. In this section I consider these arguments about well-being and disability more broadly by exploring the concept of the disability paradox. This phrase was coined in 1999 by Albrecht and Devlieger when they introduced empirical evidence supporting the fact that many disabled people rated their quality of life as good or excellent, although external observers imagined them to have an 'undesirable daily existence. ${ }^{86}$ This paper also confirmed that there was a 'decided negative bias in the attitudes and expectations of the public and health-care workers towards people with disabilities' which increased if the disability was visible or associated with stigmatisation and decreased through close contact with the disabled..$^{87}$ This phenomenon, the so-called disability paradox, consists, first, in the fact that although the disabled people surveyed reported problems related to discrimination, living activities and society they nevertheless reported excellent or good quality of life. ${ }^{88}$ Second, it consists in the fact that the non-disabled, including physicians and healthcare workers, do not believe this to be true and rate the same people as having an unsatisfying quality of life. ${ }^{89}$

Furthermore, non-disabled people, when asked to imagine the well-being of people with certain kinds of disabilities, tend to imagine it to be far worse than it is. More recent studies have shown that even in states of illness that healthy observers rate as being worse than death, the people with the actual conditions reported similar levels of well-being as the healthy counterparts (an exception to this is pain, which does seem to consistently lower levels of happiness).

Findings from the field of hedonic psychology (nicknamed 'the science of happiness') suggest that we are surprisingly bad at predicting what will make us happy and at estimating our levels of happiness in certain situations. I often 
think that a large (ideally stuffed crust) Domino's pizza is going to make me happy and am inevitably disappointed to feel less than happy after finishing one. One explanation of this phenomenon is that we basically are not good at working out what is going to make us happy. As Wasserman and Asch explain: 'whole disciplines have emerged - hedonic psychology and happiness science - that find that normal functioning and health (as well as wealth and professional success) have far less effect on (self-reported) well-being that commonly assumed. ${ }^{90}$

A 2010 paper by Ron Amundson explored this in relation to the question of whether we should believe the claims of the disabled about their own levels of happiness. Amundson explored the hedonic psychology studies related to hedonic adaptation: the idea that we adjust our levels of happiness back to their former level after a life event that has raised or lowered them. Related to this is the fact that extreme changes in happiness levels do not tend to last very long. Subjective happiness (he argues) does not result from the accumulation of hedonically positive life factors, but rather from our psychological reactions to those circumstances. ${ }^{91}$

These findings have surprising implications for the way that we think about disability and health, for the way we currently organise funding within the health service and for the priorities we focus on in our own lives. For instance, fluctuations in happiness levels resulting from changing circumstances may not last very long. You may want to win the lottery but any elevated happiness resulting from your win will only last a few years, then you will be back to the same state of mind as before. On the flip side, this also holds for the experience of severe illness or disability. ${ }^{92}$ Our health and our wealth may not be as important as our responses to the challenges we are presented with. For example, one respondent to the original 1999 survey explained:

After my wreck with a truck on the Kennedy, I realized I couldn't move my legs. I thought that my life was over. But during rehab and after I came back home I had plenty of time to think. I still had my mind. My body was in a wheelchair but I could still be a father, husband, son, and have friends. I could coach my daughter's softball team and I'm in training to be a counsellor. I can do it. I have a life. ${ }^{93}$

Another respondent elucidated: 'Other people can't understand why I am so happy. They don't have the same appreciation of life. They would have to understand the satisfaction of using all my resources to conquer each day of challenges. ${ }^{94}$ Both these responses highlight the role of challenge as key, which has made some suggest that it is the experience of working towards a goal that truly brings happiness. 
More widely, philosopher Havi Carel has discussed more recent studies of objective and subjective well-being that show medical conditions do not generally impact on overall happiness scores. ${ }^{95}$ She argues that one of the reasons why there is such a gulf between insider and outsider perspectives of illness is that healthy people weigh the importance of the illness far too heavily based on popular (prejudiced) media representations, a phenomenon known as 'the focusing illusion'. In addition, she points out that the imaginations of healthy people simply do not have the capacity of understanding the lived experience of situations so abstracted from their own lives, or, indeed, the habit of doing so. ${ }^{96}$ That is: 'Healthy people spend less time imagining themselves as old and unwell, or diagnosed with a serious illness, than they do imagining themselves playing post-retirement golf in the Florida sunshine. ${ }^{97}$

However, when presented with the disability paradox, some scholars, particularly in bioethics, have drawn on Jon Elster's 1983 work on rationality, Sour Grapes. ${ }^{98}$ In this work Elster initially draws on the fable of the fox and the grapes, in which the fox wants to eat some grapes, cannot reach the grapes they desire and so concludes that they were sour and in fact they did not want them after all. Elster's description of adaptive preferences then suggests that while the fox is pretending not to like the grapes he cannot have, a person with adaptive preferences truly does prefer what they can have over that which they cannot. In other words, they do not know what they are missing, having never experienced it.

Barnes counters this kind of criticism, arguing that 'the problem with the adaptive preference model is that it allows us to dismiss certain kinds of testimony as irrational or misleading. And so the adaptive preference model can quickly become a way of defending the moral status quo."99 Moreover, Barnes points out that 'it's simply false that all disabled people who express disabilitypositive views - including the view that they wouldn't want to become nondisabled - don't know what it's like to be non-disabled. And that's because such views are expressed by those with acquired disabilities as well as those with congenital disabilities. ${ }^{100}$ Lastly, Barnes argues that the adaptive preferences notion can hold without necessarily connoting either denial or irrationality, making the point that we all adapt based on the body and environment we are in. ${ }^{101}$ Indeed it would be deeply irrational not to do so. For example, I once wanted to be a ballet dancer but considering my aforementioned lack of flexibility, my great dislike of dieting and lack of rhythm, it would seem very strange if I had continued to work towards this goal. ${ }^{102}$

Shakespeare also points out that most of the things that we value most highly for happiness (such as meaningful relationships, being valued, fulfilment of goals) are still accessible to the disabled: 'disability usually does not 
have to equate to exclusion from most of what makes life good.' ${ }^{103}$ Carel relates well-being within illness to adaptation, accommodation and resilience and she explains that there are three main ways in which illness can increase fulfilment. First, there is evidence to show that facing adversity reveals hidden but genuine strengths and creates new confidence. Second, relationships become stronger and more authentic. Third, a new focus on the present moment leads to greater enjoyment of current experiences. ${ }^{104}$ She concludes with the beautifully expressed point that:

If we take seriously the phenomenological approach to illness and the robust evidence that ill people (and others who face adversity) are no less happy than other people, we can conclude that paying close attention to such claims may yield important insights about the experience of illness. If happiness is an achievement that requires thought, planning and work, this view contributes to our understanding of why illness does not affect long-term well-being. Illness provides us with a context and opportunity for the kind of reflection and revaluation that are the condition for and prelude to happiness. ${ }^{105}$

This section therefore reinforces the need for epistemic humility with respect to our pre-theoretical judgements about disability. Furthermore, if part of our theoretical task is to analyse the norms and practices (and in particular the instruments of medical science) which shape why we take certain bodies to matter for being categorised as disabled, then we also need to consider how our judgements about well-being are formed.

\section{Disbelief and epistemic injustice}

This reflection on the importance of taking seriously the accounts of others relates to a more insidious response to the disability paradox, which is simply to react with dismissal and disbelief. As Shakespeare brutally but amusingly puts it, 'Perhaps these cheerful people with disabilities are deluding themselves and others. ${ }^{106}$ Such disbelief is a paradigm example of epistemic injustice towards the disabled. Epistemic injustice is a concept developed by Miranda Fricker. She pointed out that in addition to the social or political injustices faced by minority groups, they can also experience epistemic injustice. She splits this into testimonial and hermeneutical injustice. The former is concerned with situations when people are unable to access a shared understanding of their social experience due to prejudiced resources. Similarly, testimonial injustice describes the prejudices that give less credibility to a speaker's assertions because their capacity 'to know' or 'to impart' is doubted. This phenomenon has been explored in relation to healthcare conditions that might specifically 
reduce credibility, such as chronic fatigue and mental health illnesses. ${ }^{107}$ Like invisible disability, the difficulty of securing a trusted instrumental diagnosis exacerbates epistemic injustice. More recently, it has been argued that there are distinctive features of disabled life that promote a specific kind of epistemic injustice. ${ }^{108}$ As Barnes points out in relation to disbelief, 'we ought to take disabled people as very good sources of evidence about what it is like to be disabled. Or we at least ought to take them as better sources of evidence than the beliefs of the non-disabled about what is common sense. ${ }^{109}$ And yet, the non-disabled often disagree with disabled people's assessments of their own lives, experiences, needs and knowledges. Jackie Leach Scully has also raised the important point that testimonial injustice can be further inflicted on the disabled through the procedures around claiming social support. ${ }^{110}$ And yet, crucially, she elucidates the fact that various kinds of impairments can actually lead to the creation of distinctive knowledge, for example about their condition and the assistive technology that may be associated with it. Not only from their experience and familiarity with their condition, but through their embodied knowledge of exactly what works for them.

This understanding is akin to Margaret Lock's concept of 'local biologies', which denotes the way in which 'the embodied experience of physical sensations, including those of well-being, health, illness, and so on, is in part informed by the material body. ${ }^{111}$ Local biologies are thus linked with both the experience and the interpretation of sensations. This has important ramifications for the way we think about 'lay epistemologies' of health. In this sense, it is not that certain groups do not have symptoms and understandings of their meanings, it is that their interpretations are not heeded by the dominant discourse. In Fricker's conceptualisation of hermeneutical epistemic injustice, marginalised social groups are subjected to epistemic harms due to a silence a gap in knowledge. Yet these 'local biologies' are most usefully conceptualised within the framework suggested by Kirstie Dotson, which has identified the way that power affects the extent to which the dominant discourse considers 'alternative epistemologies, counter mythologies, and hidden transcripts that exist in hermeneutically marginalised communities among themselves. ${ }^{112}$ It is this framework that Braun and Kopinski draw on to explain the normalisation of suffering among communities of mine-workers, arguing that 'publiclyfunded science privileges certain accounts of disease and excludes other accounts, such as those of the asbestos workers on the mines.' ${ }^{113}$ As Chapter 5 of this book will similarly argue, the miners involved in the researches into pneumoconiosis in south Wales had nuanced and sophisticated awareness of their breathlessness, but the MRC was unable to standardise this type of 
knowledge into the categorisation systems required for objectivity and compensation calculability. The spirometer was thus embraced as an objective marker of disability that could be utilised in the complex industrial compensation network. Similarly, I argue in Chapter 4 that the audiometer was used over the arguably more clinically useful tuning fork because it provided singlenumber evidence of hearing levels which could be used to negotiate compensation claims and guard against malingerers and 'hysterical' deafness. Given that social (and indeed oppressive) forces play such a fundamental role in constructing disability, this enhances the possibility of a significant threat of epistemic injustice. If the medical sciences are solely working with a naturalistic conception of disability, this heightens the likelihood of this form of injustice manifesting.

\section{Conclusion}

We need to question the extent to which measurements can tell us something 'real or true' about the human body in cases when easily quantifiable measurements of easily recognisable groups are artificially privileged. In this chapter I have argued that the naturalist conception of disability is undermined by the way in which the thresholds of normalcy are statistically constructed. This attack is mounted on two fronts. First, I draw attention to the ways in which the representative subjects used to create the statistical average can distort the threshold of normalcy. This is the situation outlined in Chapter 3, in my exploration of how the measure of normal hearing was defined using the measures of just ten 'normal' male ears. Second, I argue that the varied utilisation of different reference classes creates a problem of misrepresentation, as using arbitrarily defined social groups can promote essentialist thinking about 'natural' differences between these groups and thereby disguise environmental and social impacts on health.

This history should make us cognisant of the danger of essentialising social categories, not only in terms of racial or sexual profiling, but also in terms of disability. My views here are therefore aligned with those of Amundson, who explains that while the concept of normality invokes no essentialist casual powers, in that the functional type does not explain biological form. I am concerned, however, that once the concept is introduced and reified, it is itself used in casual explanations of social phenomena. It is used to explain and rationalize the social disadvantages of people labelled abnormal. ${ }^{114}$ Crucially, however, this works two ways. While we ought to be concerned about essentialising social categories, we also need to ensure relevant groups are classified 
as such when it matters. As this book will demonstrate, the pliability and mutability of relevant reference classes meant that these classification systems were integral to the production of biopower in twentieth-century Britain.

\section{Notes}

1 Dr Tomas Chamorro-Premuzic has drawn attention to the recent nature of this phenomenon and related it to the impact of individually targeted marketing and especially the specificity of online targeted marketing. He pointed out on BBC Radio 4 that 'this is a fairly recent phenomenon, a hundred years ago if you ask people: "are you destined to be different or destined to be famous or destined to be special?" - about 20 or $30 \%$ of people said yes, in the 50 s that number went up to $50 \%$, in the 80 s it went up to $70 \%$ and right now it's about $85 \%$. BBC Radio 4, 'Average', The Digital Human, series 15. Accessed June 2019. www.bbc.co.uk/ programmes/m0000qvy.

2 Fricker, M., Epistemic Injustice: Power and the Ethics of Knowing (Oxford: Oxford University Press, 2007).

3 Carel, H., and Kidd, I., 'Epistemic Injustice in Healthcare: A Philosophical Analysis', Medicine, Health Care and Philosophy, 17:4 (2014), 529-540.

4 Scully, J. L., 'From "She Would Say That, Wouldn't She?" to "Does She Take Sugar?” Epistemic Injustice and Disability', International Journal of Feminist Approaches to Bioethics, 11:1 (2018), 106-124.

5 Carel, H., 'Breathless: Philosophical Lessons from Respiratory Illness', Journal of Medical Humanities, 6:1 (2014), 1-6.

6 See Barnes, E., The Minority Body (Oxford: Oxford University Press, 2016) and Kingma, E., 'Health and Disease: Social Constructivism as a Combination of Naturalism and Normativism', in H. Carel and R. Cooper (eds), Health, Illness and Disease: Philosophical Essays (Durham: Acumen Publishing, 2013), pp. 37-56.

7 Kingma, E., 'Paracetamol, Poison, and Polio: Why Boorse's Account of Function Fails to Distinguish Health and Disease', British Journal for the Philosophy of Science, 61:2 (2010), 241-264, p. 242.

8 Boorse, C., 'Health as a Theoretical Concept', Philosophy of Science, 44:4 (1997), 542-573.

9 Boorse, C., 'Disability and Medical Theory', in D. Ralston and J. Ho (eds), Philosophical Reflections on Disability (Dordrecht: Springer, 2010), pp. 55-88, p. 104.

10 Kuhane, G., and Savulescu, J., 'The Welfarist Account of Disability', in K. Brownlee and A. Cureton (eds), Disability and Disadvantage (Oxford: Oxford University Press, 2009), pp. 1-37, p. 5.

11 Boorse, C., 'A Second Rebuttal on Health', Journal of Medicine and Philosophy, 39:6 (2014), 683-724.

12 Wakefield, J. C., 'The Biostatistical Theory versus the Harmful Dysfunction Analysis, Part 1: Is Part-Dysfunction a Sufficient Condition for Medical Disorder?', Journal of Medicine and Philosophy, 39:6 (2014), 648-682, p. 649. 
13 Boorse, 'Disability and Medical Theory', p. 69.

14 Ibid.

15 Cooper, R., 'Disease', Studies in History and Philosophy of Biological and Biomedical Sciences, 22:2 (2002), 263-282.

16 Boorse does clarify in his 2014 rebuttal that the BST was always meant to be dynamic.

17 My extreme fear that something like this or worse would happen is enough to ensure that I have never indulged in this kind of activity.

18 Kingma, 'Paracetamol, Poison, and Polio', p. 248.

19 Ibid., pp. 248-249.

20 Cooper, 'Disease', p. 263.

21 Cooper, R., 'Shifting Boundaries Between the Normal and the Pathological: The Case of Mild Intellectual Disability', History of Psychiatry, 25:2 (2014), 171-186.

22 Amundson, R., 'Against Normal Function', Studies in History and Philosophy of Biological and Biomedical Sciences, 31:1 (2000), 33-53, p. 35.

23 Barnes, The Minority Body, p. 14.

24 Ibid., p. 15.

25 Ibid.

26 Ibid., p. 16.

27 Ibid., p. 17.

28 Amundson, 'Against Normal Function', p. 45.

29 Boorse, 'A Second Rebuttal'.

30 Kingma, 'Paracetamol, Poison, and Polio', p. 243.

31 Chin-Yee, B., and Upshur, R. E. G., 'Re-Evaluating Concepts of Biological Function in Clinical Medicine: Towards a New Naturalistic Theory of Disease', Theoretical Medicine and Bioethics, 38:4 (2017), 245-264, p. 247.

32 Cooper, 'Disease', p. 266.

33 Kingma, E., 'What Is It to Be Healthy?', Analysis, 67:294 (2007), 128-133, p. 128.

34 Epstein, Inclusion, p. 10.

35 Shim, Heart-Sick, p. 18.

36 Ibid., p. 89.

37 Ibid., p. 129.

38 Epstein, Inclusion, p. 255.

39 Shim, Heart-Sick, p. 194.

40 Epstein, Inclusion, p. 11.

41 See Ahrens, K. A., Rossen, L. M., and Simon, A. E., 'Relationship between Mean Leucocyte Telomere Length and Measures of Allostatic Load in US ReproductiveAged Women, NHNES 1999-2002', Paediatric and Perinatal Epidemiology, 30:4 (2016), 325-335, and Szanton, S. L., Gill, J. M., and Allen, J. K., 'Allostatic Load: A Mechanism of Socioeconomic Health Disparities?', Biological Research for Nursing, 7:1 (2010), 7-15.

42 Epstein, Inclusion, p. 144.

43 Ibid., pp. 210-211. 
44 Chow-White, P. A., and Green, J. R., 'Data Mining Differences in the Age of Big Data: Communication and the Social Shaping of Genome Technologies from 1998 to 2007', International Journal of Communication, 7 (2013), 556-583, p. 576.

45 Ibid., p. 556.

46 Noble, S. U., Algorithms of Oppression: How Search Engines Reinforce Racism (New York: New York University Press, 2018) and Hoffman, A. L., 'Data Violence and How Bad Engineering Choices Can Damage Society', Medium, 30 April 2018. https://medium.com/s/story/data-violence-and-how-bad-engineering-choicescan-damage-society-39e44150e1d4. Accessed July 2019.

47 Bowker, G. C., and Star, S. L., Sorting Things Out: Classification and Its Consequences (Cambridge, MA: MIT Press, 2000), p. 10.

48 Ibid., p. 110.

49 For comparative arguments about the objectivity and power of numbers in biopolitics see Porter, 'Measurement, Objectivity, and Trust' and Hacking, 'Biopower and the Avalanche of Printed Numbers'

50 Amundson, 'Against Normal Function', p. 34.

51 Epstein, 'Bodily Differences and Collective Identities', p. 195.

52 Kingma, 'Health and Disease', p. 44.

53 Braun, Breathing Race into the Machine.

54 Epstein, Inclusion, p. 24.

55 Braun, Breathing Race into the Machine.

56 Ibid., p. 205.

57 For the original mapping of intersectionality see Crenshaw, K., 'Mapping the Margins: Intersectionality, Identity, Politics, and Violence against Women of Color', Stanford Law Review, 43:6 (1991), 1241-1299, and for more of my analysis using this framework see Chapter 5 .

58 Quoted in Shakespeare, T., 'Nasty, Brutish, and Short? On the Predicament of Disability and Embodiment', in J. E. Bickenback, F. Felder and B. Schmitz (eds), Disability and the Good Human Life (Cambridge: Cambridge University Press, 2014), pp. 93-112, p. 95.

59 Daniels, N., 'Normal Functioning and the Treatment-Enhancement Distinction', Cambridge Quarterly of Healthcare Ethics, 9:3 (2000), 314-315; for a longer explanation of this view see Daniels, N., Just Health Care (Cambridge: Cambridge University Press, 1985).

60 Historians and philosophers who have applied this kind of analysis to hysteria include Elaine Showalter in Showalter, E., The Female Malady: Women, Madness and English Culture, 1830-1980 (London: Penguin Books, 1987); Andrew Scull in Scull, A., Hysteria: The Disturbing History (Oxford: Oxford University Press, 2009); and Jan Goldstein in Goldstein, J., Hysteria Complicated by Ecstasy: The Case of Nanette Leroux (Princeton, NJ: Princeton University Press, 2010).

61 Cooper, 'Disease'.

62 Cooper, R., 'Are Culture-Bound Syndromes as Real as Universally-Occurring Disorders?', Studies in History and Philosophy of Science Part C: Studies in History and Philosophy of Biological and Biomedical Sciences, 41:4 (2010), 325-332. 
63 Cooper, 'Disease'.

64 See Barnes, The Minority Body and Kingma, 'What Is It to Be Healthy?'.

65 Kingma, 'Health and Disease'.

66 Chin-Yee and Upshur, 'Re-Evaluating Concepts of Biological Function', p. 247.

67 See the introduction to Shakespeare, T., Disability Rights and Wrongs Revisited (London: Routledge, 2nd edn, 2013).

68 See Shakespeare, T., 'The Social Model of Disability: An Outdated Ideology?', Research in Social Science and Disability, 2 (2002), 9-28.

69 Chapman, R., 'Neurodiversity, Disability, Wellbeing', in N. Chown, A. Stenning and H. Rosquvist (eds), Neurodiversity Studies: A New Critical Paradigm (London: Routledge, forthcoming).

70 It is important to note that her book focuses specifically on physical disability, and whether the value-neutral model is valid in cases such as learning disability, chronic illness or mental illness is not clear.

71 Kuhane and Savulescu, 'The Welfarist Account of Disability'.

72 Barnes, The Minority Body, p. 12.

73 Shakespeare, 'Nasty, Brutish, and Short?', p. 93 This convention recently condemned Conservative austerity policies c. 2008-19 for their overtly negative impacts on the disabled.

74 Ibid., pp. 101-102.

75 Barnes, The Minority Body, p. 20-21.

76 Ibid., p. 43.

77 Ibid., p. 72.

78 Gould, The Mismeasure of Man, p. 121.

79 This was very troubling for nineteenth-century prison doctors as the brains of the criminals they autopsied tended to be large (because brains expand when a person is hanged).

80 Broca quoted in Gould, The Mismeasure of Man, p. 135.

81 Barnes, The Minority Body, p. 72 (ellipses added for clarity).

82 Ibid., p. 37.

83 Ibid., p. 38.

84 Ibid., p. 41.

85 Ibid., pp. 71-72.

86 Albrecht, G. L., and Devlieger, P. J., 'The Disability Paradox: High Quality of Life against All Odds', Social Science and Medicine, 48:8 (1999), 977-988, p. 977.

87 Ibid., p. 978 and p. 979.

88 Ibid., p. 982.

89 Ibid.

90 Wasserman, D., and Asch, A., 'Understanding the Relationship between Disability and Well-Being', in J. E. Bickenback, F. Felder and B. Schmitz (eds), Disability and the Good Human Life (Cambridge: Cambridge University Press, 2014), pp. 139167, p. 141.

91 Amundson, R., 'Quality of Life, Disability, and Hedonic Psychology', Journal for the Theory of Social Behaviour, 40:4 (2010), 374-392, p. 379. 
92 Carel, H., 'Ill, but Well: A Phenomenology of Well-Being in Chronic Illness', in J. E. Bickenback, F. Felder and B. Schmitz (eds), Disability and the Good Human Life (Cambridge: Cambridge University Press, 2014), pp. 243-270, p. 253.

93 Albrecht and Devlieger, 'The Disability Paradox', p. 983.

94 Ibid., p. 984.

95 Carel, 'Ill, but Well', p. 252.

96 Ibid., pp. 254-255.

97 Ibid., p. 254.

98 Elster, J., Sour Grapes: Studies in the Subversion of Rationality (Cambridge: Cambridge University Press, 2016).

99 Barnes, The Minority Body, p. 134.

100 Ibid., p. 104.

101 Ibid., p. 125.

102 Barnes draws on Martha Nussbaum's work on capabilities to make this point. See Barnes, The Minority Body, p. 128.

103 Shakespeare, 'Nasty, Brutish, and Short?', p. 100.

104 Carel, 'Ill, but Well', pp. 257-258.

105 Ibid., p. 266.

106 Shakespeare, 'Nasty, Brutish, and Short?', p. 97.

107 Carel and Kidd, 'Epistemic Injustice in Healthcare' and Blease, C., Carel, H., and Geraghty, K., 'Epistemic Injustice in Healthcare Encounters: Evidence from Chronic Fatigue Syndrome', Journal of Medical Ethics 43:8 (2016), 549557.

108 Scully, 'From "She Would Say That, Wouldn't She?".

109 Barnes, The Minority Body, p. 142.

110 Scully, 'From "She Would Say That, Wouldn't She?"'.

111 Lock, M., 'The Tempering of Medical Anthropology: Troubling Natural Categories', Medical Anthropology Quarterly, 15:4 (2001), 478-492, p. 483.

112 Dotson, K., 'A Cautionary Tale: On Limiting Epistemic Oppression', Frontiers: A Journal of Women Studies, 33:1 (2012), 24-47, p. 31.

113 Braun, L., and Kopinski, H., 'Casual Understandings: Controversy, Social Context, and Mesothelioma Research', Biosocieties, 13:3 (2018), 557-579, p. 560.

114 Amundson, 'Against Normal Function', p. 37. 